\title{
Role of Intraoperative Red Cell Salvage and Autologus Transfusion in Metastatic Spine Surgery: A Pilot Study and Review of Literature
}

\author{
Harinder Gakhar, Munzer Bagouri, Rajendranath Bommireddy, Zdenek Klezl \\ Department of Trauma and Orthopaedics, Royal Derby Hospital, Derby, UK
}

\begin{abstract}
Study Design: Prospective cohort study.
Purpose: There has been no research examining the use of intraoperative cell salvage during metastatic spinal surgery. The present work is a pilot study investigating the role of cell salvage during metastatic spine surgery.

Overview of Literature: There is no spinal literature about role of cell salvage and autologus transfusion in metastatic spinal cancer.

Methods: Sixteen spinal metastases patients who received red cell salvage using a leucocyte depletion filter were enrolled. Of these, ten patients who received salvaged blood transfusion were included in the final analysis. Data collection involved looking at the case notes, operating room records and the prospectively updated metastatic spinal cancer database maintained in the spinal department. Cell salvage data was recovered from the central cell salvage database maintained in the anesthetic department.

Results: Amount of salvaged blood ranged from 120 to $600 \mathrm{~mL}$ (average, $318 \mathrm{~mL}$ ). The average drop in hemoglobin was 1.65 units (range, $0.4-2.7$ units). Three patients (30\%) required postoperative allogenic blood transfusion. The average follow up was 9.5 months (range, 6-26 months). One patient developed new lung metastasis, at seven months. No patient developed new liver metastases. Preoperatively, six patients had diffuse skeletal metastases. Of this subgroup, three developed new skeletal metastases. No cases showed any wound related problems in the postoperative period.

Conclusions: In our study transfusion of intraoperatively salvaged blood did not result in disseminated metastatic cancer. We would suggest that red cell salvage might have a role during metastatic spine surgery.
\end{abstract}

Keywords: Operative blood salvage; Spinal cord compression

\section{Introduction}

Historically, malignancy has been considered as an absolute or relative contraindication for Intraoperative cell salvage [1]. Intraoperative red cell salvage is routinely used in prostate cancer, gynae-oncology and liver tumor surgery [2]. It also has its proponents in the field of revi- sion hip surgery [3]. The role of cell salvage has also been investigated in adult lumbar spine fusion and pediatric scoliosis surgery $[4,5]$.

Metastatic spinal tumors are hypervascular in a large percentage of cases [6,7]. Surgery on such tumors usually leads to heavy blood loss and the need for allogenic blood transfusion. There have been a number of reports

Received Aug 8, 2012; Revised Aug 23, 2012; Accepted Aug 30, 2012

Corresponding author: Harinder Gakhar

Department of Trauma and Orthopaedics, Royal Derby Hospital,

Uttoxeter Rd, Derby, DE22 3NE, UK

Tel: +44-7598-281538, Fax: +44-1685-728123, E-mail: gul34@yahoo.com 
highlighting the risks of allogenic transfusion, which include immuno-modulation. This may lead to the risk of infection or even tumor recurrence in metastatic spinal surgery [1].

Cell salvage has been demonstrated to be a safe and effective method of reducing allogeneic blood transfusion requirements in adult elective surgery, with stronger evidence for its use in cardiac and orthopedic surgery [2]. As far back as 1993 it was conclusively shown that allogenic blood transfusion is linked to higher rates of postoperative infection [8].

Up to date, the role of red cell salvage in metastatic spine surgery has not been investigated. The current paper forms a preliminary study of the role of cell salvage during metastatic spine surgery, with a relevant literature review also being provided.

\section{Materials and Methods}

This is a single centre two surgeon prospective case series. Between 2008 and 2010, all cases of metastatic spinal cord compression in which we used red cell salvage during surgery were enrolled. Data collection involved looking at the case notes, operating room records and the prospectively updated metastatic spinal cancer database maintained in the spinal department. Cell salvage data was recovered from the central cell salvage database maintained in the anesthetic department.

In all cases, leukocyte depletion filters were used as routine. Along with this we used a double suction technique, through which we achieved low-pressure suction so as to suck the blood for cell saving. In this method, when the tumor tissue is reached a second wall suction is used, the contents of which are not used for cell salvage. This allows an overall reduction in the rate of contamination of the salvaged blood.

The primary outcome measure was the percentage of patients needing postoperative allogenic blood transfusion. Other measures that were looked at were the pre and postoperative hemoglobin levels and lowered haematocrit levels. We also looked at any postoperative complications, including wound infection.

We also analyzed postoperative computed tomography (CT) scans of the chest and abdomen and magnetic resonance scans of the whole spine to check for any new metastatic lesions, as compared to the preoperative scans.
Table 1. Table showing site of primary tumours and vertebral levels involved

\begin{tabular}{cc} 
Primary tumour & Levels involved \\
\hline Renal-2 & Lumbar-5 \\
\hline Breast-3 & Thoracic-4 \\
\hline Myeloma-2 & Both-1 \\
\hline Prostate-2 & \\
\hline Lung-1 & \\
\hline
\end{tabular}

\section{Results}

Between 2008 to 2010, 16 cases ( 8 males and 8 females) of metastatic spinal cord compression in which we made use of cell saving during surgery were enrolled. Six cases showed insufficient blood collection and were thus not included in the final analysis. The average age of patients was 66.6 years (range, $45-82$ years). Seven patients had single level involvement, and three had two level involvement. The primary lesions were mainly renal, breast, myeloma, prostate and etc. (Table 1).

Seven patients underwent posterior only procedures, and three underwent both anterior and posterior procedures.

Ten patients received salvaged red cell transfusion. Blood loss during surgery ranged between 350 to 900 $\mathrm{mL}$ (average, $571 \mathrm{~mL}$ ). The amount of blood transfused ranged from 120 to $600 \mathrm{~mL}$ (average, $318 \mathrm{~mL}$ ). The average drop in hemoglobin as compared to the preoperative value was 1.65 units (range, $0.4-2.7$ units). Three patients (30\%) required postoperative allogenic blood transfusion.

The average follow-up duration was 9.5 months (range, 6-26 months). All patients received CT scan of the chest and abdomen and magnetic resonance imaging scan of the spine at four months or later during their follow up. During the follow up staging, one patient developed new lung metastasis, at seven months. None of our patients developed new liver metastases. Preoperatively, six patients had diffuse skeletal metastases. Of this subgroup, three went on to develop new skeletal metastases (Table 2). All patients showed satisfactory wound healing with no infections or wound breakdowns.

\section{Discussion}

Cell salvage is now being used in most surgical specialties $[4,5,9]$. The use of Intraoperative cell salvage and 


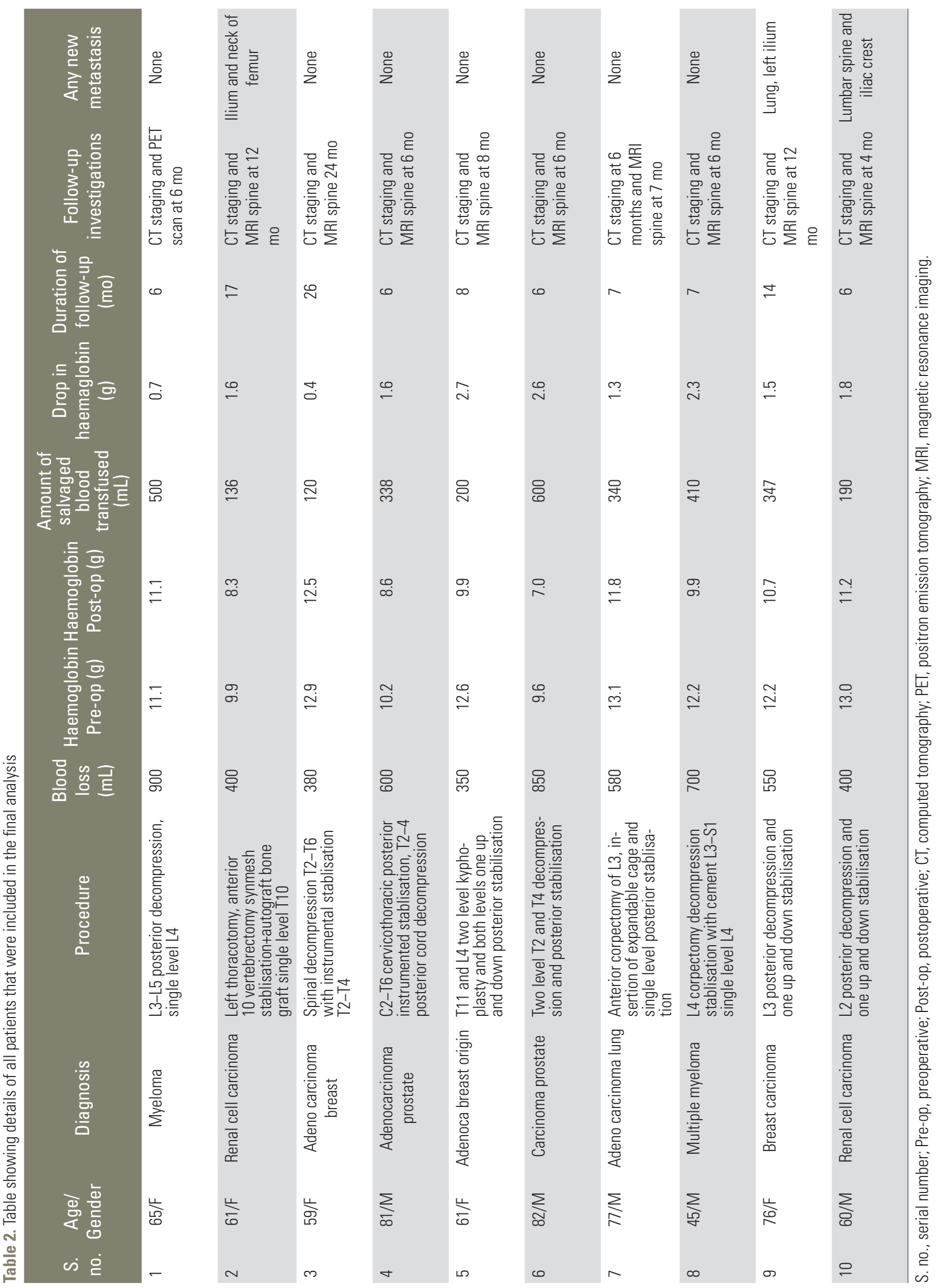


autologous blood transfusion has become an important method of blood conservation. The use of cell salvage in combination with a leukocyte depletion filter appears to be safe in for obstetric use and in cases of malignancy. It has been demonstrated that cell salvage reduces the need for allogeneic blood transfusion in revision hip [3] and knee replacement surgery $[10,11]$. The only absolute contraindication to the use of cell salvage and autologous blood transfusion is patient refusal [2].

Prior to this case series, there has been no published literature about use of cell salvage in metastatic spinal cancer surgery. In this study only $30 \%(n=3)$ of patients required postoperative allogenic transfusion. This is also shown by the fact that the average drop in hemoglobin was 1.65 units (range, 0.4-2.7 units). These results should be considered in light of the fact that, on average, after major spine surgery transfusion rates may be as high as $50 \%$ to $80 \%$ [12].

The most obvious concern that surgeons may have about using cell salvage in cases of cancer is the disseminated spread of the disease process. However, with the development of new cell salvage techniques and special leukocyte depletion filters, cell salvage is being used in different oncological situations. Leucodepletion is thought to improve cell salvage safety and reduce side effects. Leukocyte depletion filters consist of a sieve with a negative surface charge, with this method having been demonstrated to be efficient at removing white blood cells, tumor cells, amniotic fluid, and microorganisms [2].

During this study's follow up period, only one patient developed new lung metastasis, at seven months. None of our patients developed any new liver metastases. Preoperatively, six patients had diffuse skeletal metastases. Of this subgroup, three patients went on to develop new skeletal metastases at different stages of follow up. The remaining four patients did not develop any new lesions during follow up. There were no cases in which disseminated skeletal metastases developed during the follow up.

Hansen et al. [13] suggested that malignant cells can regularly be identified in the blood lost during tumor surgery and are different from circulating tumor cells. These cells are of concern, since at the surgical site they may cause local tumor recurrence, or in the salvaged blood they may cause hematogenic metastasis after retransfusion.

Catling et al. [14] investigated the ability of leukocyte depletion filters to remove tumor cells from salvaged blood. Blood samples were obtained before operation, from the cell saver before and after processing and after passing through a leukocyte depletion filter. Viable tumor cells were found in $4 \%$ of preoperative samples, in $68 \%$ of cell saver reservoirs before processing, and in $62 \%$ after processing. After the salvaged blood was passed through the filter, the researchers found no tumor cells. However, they did find tumor cell fragments, but these were unable to cause metastases [14]. In 1991, Miller et al. [15] carried out their landmark research that proved that the use of cell saving techniques in combination with RC-100 filters could be suitable for use during the surgical treatment of malignant disease.

In 2008, the National Institute for Health and Care Excellence (NICE) [16] published guidelines endorsing the use of intraoperative cell salvage in combination with leukocyte depletion filter for radical prostatectomy and cystectomy. The use of cell salvage during liver transplantation for hepatocellular carcinoma has been found to be cost-effective [17]. Liang et al. [18] showed that the use of leukocyte depletion filter was efficient in removing tumor cells in liver transplant surgery for hepatocellular cancers.

A prospective observational study of 308 patients found that allogeneic blood transfusion was associated with an increased incidence of postoperative infection when compared with autologous transfusion $(p=0.0053)$ [19]. It is known that immunomodulation occurs with allogeneic transfusion, but the issue of whether this immunomodulation affects tumor growth is unresolved. There is evidence to suggest that patients who receive allogeneic blood in the context of cancer surgery have worse outcomes $[20,21]$. There is also evidence that the rate of postoperative infection is reduced in cancer surgery if autologous blood is used [8], but whether or not there is a beneficial effect on malignant recurrence is less clear [22].

There are many potential complications associated with cell salvage, including non-immune hemolysis; air embolus; febrile non-hemolytic transfusion reactions; mistransfusion; coagulopathy; contamination with drugs, cleansing solutions and infectious agents, and incomplete washing leading to contamination with activated leucocytes, cytokines, and other microaggregates [2]. Work comparing cell salvaged blood with allogeneic blood has demonstrated that the former shows increased mean erythrocyte viability and increased 2,3-disphosphoglycerate and adenosine triphosphate levels [2]. Complications associated with the use of cell salvage are rare and studies 
have shown no increase in the rate of complications in patients who receive cell salvage. However, when patients are auto-transfused with large volumes, this is often accompanied by coagulopathy as the washing process discards all platelets and clotting factors, leaving only the red cells re-suspended in normal saline.

There is strong literature based evidence to support the use of cell salvage in primary cancer surgery. Yet in spite of our best efforts, we could not find any published reports about the use of cell salvage in cases of metastatic cancer. In spinal metastases cases, the cancer has already spread via the hematogenous route. Therefore the fear of the disseminated spread of cancer is likely to be of a smaller magnitude in metastatic cancers cases when compared to cases of cancers of primary origin.

\section{Conclusions}

There has been as yet no published evidence about the role of cell salvage during metastatic spine surgery. Based on our study, we suggest that there may be a role for routine red cell salvage in metastatic spine surgery. However, it will be a long while before cell salvage is established as routine protocol in metastatic spine surgery. Future prospective randomized trials may help to clarify this scenario and the issues involved.

\section{Conflict of Interest}

No potential conflict of interest relevant to this article was reported.

\section{References}

1. Esper SA, Waters JH. Intra-operative cell salvage: a fresh look at the indications and contraindications. Blood Transfus 2011;9:139-47.

2. Ashworth A, Klein AA. Cell salvage as part of a blood conservation strategy in anaesthesia. Br J Anaesth 2010;105:401-16.

3. Bridgens JP, Evans CR, Dobson PM, Hamer AJ. Intraoperative red blood-cell salvage in revision hip surgery: a case-matched study. J Bone Joint Surg Am 2007;89:270-5.

4. Reitman CA, Watters WC 3rd, Sassard WR. The Cell Saver in adult lumbar fusion surgery: a cost-benefit outcomes study. Spine (Phila Pa 1976) 2004;29:1580-
3.

5. Bowen RE, Gardner S, Scaduto AA, Eagan M, Beckstead J. Efficacy of intraoperative cell salvage systems in pediatric idiopathic scoliosis patients undergoing posterior spinal fusion with segmental spinal instrumentation. Spine (Phila Pa 1976) 2010;35:246-51.

6. Truumees E, Dodwad SN, Kazmierczak CD. Preoperative embolization in the treatment of spinal metastasis. J Am Acad Orthop Surg 2010;18:449-53.

7. Schmidt R, Rupp-Heim G, Dammann F, Ulrich C, Nothwang J. Surgical therapy of vertebral metastases: are there predictive parameters for intraoperative excessive blood loss despite preoperative embolization? Tumori 2011;97:66-73.

8. Heiss MM, Mempel W, Jauch KW, et al. Beneficial effect of autologous blood transfusion on infectious complications after colorectal cancer surgery. Lancet 1993;342:1328-33.

9. Mann DC, Wilham MR, Brower EM, Nash CL Jr. Decreasing homologous blood transfusion in spinal surgery by use of the cell saver and predeposited blood. Spine (Phila Pa 1976) 1989;14:1296-300.

10. Sinclair KC, Clarke HD, Noble BN. Blood management in total knee arthroplasty: a comparison of techniques. Orthopedics 2009;32:19.

11. Shenolikar A, Wareham K, Newington D, Thomas D, Hughes J, Downes M. Cell salvage auto transfusion in total knee replacement surgery. Transfus Med 1997;7:277-80.

12. Elgafy H, Bransford RJ, McGuire RA, Dettori JR, Fischer D. Blood loss in major spine surgery: are there effective measures to decrease massive hemorrhage in major spine fusion surgery? Spine (Phila Pa 1976) 2010;35:S47-56.

13. Hansen E, Wolff N, Knuechel R, Ruschoff J, Hofstaedter F, Taeger K. Tumor cells in blood shed from the surgical field. Arch Surg 1995;130:387-93.

14. Catling S, Williams S, Freites O, Rees M, Davies C, Hopkins L. Use of a leucocyte filter to remove tumour cells from intra-operative cell salvage blood. Anaesthesia 2008;63:1332-8.

15. Miller GV, Ramsden CW, Primrose JN. Autologous transfusion: an alternative to transfusion with banked blood during surgery for cancer. Br J Surg 1991;78:713-5.

16. National Institute for Health and Care Excellence (NICE). Intraoperatice red blood cell salvage during 
radical prostatectomy or radical cystectomy (IPG258) [Internet]. London: NICE; c2013 [cited 2009 Aug 25]. Available from: http://guidance.nice.org.uk/IPG258.

17. Phillips SD, Maguire D, Deshpande R, et al. A prospective study investigating the cost effectiveness of intraoperative blood salvage during liver transplantation. Transplantation 2006;81:536-40.

18. Liang TB, Li DL, Liang L, et al. Intraoperative blood salvage during liver transplantation in patients with hepatocellular carcinoma: efficiency of leukocyte depletion filters in the removal of tumor cells. Transplantation 2008;85:863-9.

19. Innerhofer P, Klingler A, Klimmer C, Fries D, Nuss- baumer W. Risk for postoperative infection after transfusion of white blood cell-filtered allogeneic or autologous blood components in orthopedic patients undergoing primary arthroplasty. Transfusion 2005;45:103-10.

20. Francis DM. Relationship between blood transfusion and tumour behaviour. Br J Surg 1991;78:1420-8.

21. Vamvakas EC. Perioperative blood transfusion and cancer recurrence: meta-analysis for explanation. Transfusion 1995;35:760-8.

22. Heiss MM. Risk of allogeneic transfusions. Br J Anaesth 1998;81 Suppl 1:16-9. 